doi:10.1016/j.watres.2006.05.019

Copyright (c) 2006 Published by Elsevier Ltd.

\title{
Short- and long-term variations of norovirus concentrations in the Meuse river during a 2-year study period
}

\section{Therese Westrell ${ }^{a, b}$, Peter Teunis ${ }^{c}$, Harold van den Berg ${ }^{d}$, Willemijn Lodder $^{d}$, Henk Ketelaars ${ }^{e}$, Thor Axel Stenström ${ }^{a, b}$ and Ana Maria de Roda Husman $^{\text {d, } *}$}

aDepartment of Parasitology, Mycology and Water Microbiology, Swedish Institute for Infectious Disease Control (SMI), 17182 Solna, Sweden

${ }^{b}$ Department of Water and Environmental Studies, Linköping University, 58183

Linköping, Sweden

${ }^{\mathrm{C}}$ Computerization and Methodological Consultancy Unit, National Institute of Public Health and the Environment (RIVM), 3720 BA Bilthoven, The Netherlands

${ }^{\mathrm{d} M i c r o b i o l o g i c a l ~ L a b o r a t o r y ~ f o r ~ H e a l t h ~ P r o t e c t i o n, ~ N a t i o n a l ~ I n s t i t u t e ~ o f ~ P u b l i c ~}$ Health and the Environment (RIVM), 3720 BA Bilthoven, The Netherlands 'Waterwinningsbedrijf Brabantse Biesbosch (WBB), 4251 NN Werkendam, The Netherlands

Received 5 August 2004; revised 29 March 2006; accepted 19 May 2006. Available online 12 July 2006.

\begin{abstract}
Faecally impacted surface waters used for drinking water production may encompass risk for norovirus infections. To be able to assess a possible health risk, noroviruses should be quantified and fluctuations identified. In 2001, norovirus concentrations in the river Meuse displayed a seasonal distribution with high peaks during wintertime as determined by RT-PCR on serially diluted RNA. An intensified day-by-day sampling scheme in the winter of 2002/2003 revealed that the winter peak consisted of several peaks of varying duration and magnitude, possibly due to contamination events in the catchment. The highest estimated concentration was 1700 PCR-detectable units per litre (95\% CI $250-$ 8000), which if coinciding with failing treatment could lead to significant numbers in drinking water. Adaptive dynamic filtering was shown to adequately predict subsequent sample concentrations. If valid, such analyses could prove to be useful as early warning systems in risk management of water sources.
\end{abstract}

Keywords: Noroviruses; Surface water; Seasonal distribution; Peaks; Adaptive dynamic filtering 


\section{Introduction}

Noroviruses (NoV; previously Norwalk-like viruses) are the most common cause of gastroenteritis in people of all age groups (Koopmans and Duizer, 2004). The viruses belonging to the Caliciviridae are highly infectious and cause numerous outbreaks annually. The occurrence of NoV outbreaks in the population shows a seasonal pattern, mainly occurring during wintertime (Mounts et al., 2000; Lopman et al., 2004). The relative impact of waterborne NoV outbreaks in relation to other routes of transmission needs to be resolved. NoV has, however, been reported more and more frequently as an essential aetiological agent of waterborne gastroenteritis. In some of the recent NoV outbreaks, the causal relationship between a contaminated water source and faecal samples of cases could clearly be established with molecular methods (Brown et al., 2001; Anderson et al., 2003; Nygård et al., 2003; Hoebe et al., 2004). Often treatment failure or inadequate removal was implied as the cause of waterborne disease. An infected individual can shed NoV both via vomits and faeces in high numbers. The highest shedding occurs during the symptomatic phase when vomits or faeces can contain $10^{8}$ and $10^{9}$ virus particles per $\mathrm{mL}$, respectively, as estimated by electron microscopy (Hedlund, 2004). NoV shedding in faeces has also been confirmed from patients after the cessation of symptoms (Marshall et al., 2001; Rockx et al., 2002). The viruses have been detected in high levels in raw sewage (Lodder et al., 1999) as well as treated sewage (van den Berg et al., 2005). Once discharged into recipient waters, viruses can survive for long periods depending on temperature and solar irradiation (Allwood et al., 2003). NoV have been detected by RT-PCR both in fresh waters, such as rivers and lakes, and sea waters in different parts of the world (Katayama et al., 2002; Hörman et al., 2004; Lodder and de Roda Husman, 2005). To date numerous attempts to culture NoV have failed to yield replicating virions (Duizer et al., 2004) and therefore the infectivity of these viruses in environmental samples cannot be established. Human volunteer studies have shown that exposure to relatively low doses, based on NoV RT-PCR units, may lead to infection and illness (Lindesmith et al., 2003).

The aims of this study were to quantitatively describe NoV concentrations in surface water over a whole year and to perform adaptive dynamic filtering to study the occurrence of peaks and possibly their shapes/magnitude.

\section{Materials and methods}

\subsection{Sampling}

The water samples were taken from the river Meuse at the intake to the Biesbosch storage reservoirs that serve as the raw water supply for several waterworks in the southern and western parts of The Netherlands. The Meuse is a moderately polluted and highly eutrophicated river running from France, through Belgium and out to the North Sea on the coast of The Netherlands. Large volume water sampling (200-500 L) from the river was conducted monthly during year 2001. Between December 92002 and January 102003 an intensified sampling programme was carried out with weekly large volume water samples followed by small volume water samples $(10 \mathrm{~L})$ from each of the four consecutive days.

Turbidity, expressed in formazine turbidity units, FTU, was determined using the Hanna 193703 microprocessor turbidity meter (range 0.00-1000 FTU). 


\section{Virus detection}

\subsection{Concentration of water samples}

The large and small volume water samples were first concentrated by a conventional filter adsorption-elution method (Lodder and de Roda Husman, 2005). Large volume water samples were filtered and eluted at the point of sampling while $10-\mathrm{L}$ samples were processed in the laboratory. Magnesium chloride was added to a water sample to a final concentration of $0.05 \mathrm{M}(\mathrm{pH} 3.8)$ to facilitate binding to a commercial cartridge filter $(1.2 \mu \mathrm{m}$ Nominal) (Millipore, Etten-Leur, The Netherlands). Viruses were eluted from the filter with a $3 \%$ beef extract (Difco, Amsterdam, The Netherlands)/Tris solution ( $\mathrm{pH} 9.0)$. The typical retentate volume of the large volume water sample was approximately $1800 \mathrm{~mL}$ and for the 10-L water sample, this was approximately $650 \mathrm{~mL}$. The resulting retentate was neutralised (to $\mathrm{pH} 7.2$ ) and subjected to two-phase separation for molecular analysis or to culture methods.

\subsubsection{Concentration and purification of virus from the eluate by two- phase separation}

To 650-mL eluate, 1\% (w/v) Dextran T40, 10\% (w/v) PEG 6000, $0.2 \mathrm{M} \mathrm{NaCl}$ and $10 \mathrm{mM}$ phosphate buffer ( $\mathrm{pH} 7.2$ ) were added and mixed for $1 \mathrm{~h}$ at $4{ }^{\circ} \mathrm{C}$ on a horizontal shaker. The suspension was then transferred to a separation funnel and left overnight at $4^{\circ} \mathrm{C}$. After separation, the bottom phase and the interphase were harvested. Further purification was done by spin-column gel chromatography using Sephadex G200 (ICN, Zoetermeer, The Netherlands), and by ultrafiltration in a Centricon 100 microconcentrator, 100,000 MW cut-off (Amicon, Dronten, The Netherlands). The average retentate volumes were 1$5 \mathrm{~mL}$.

\subsubsection{RNA extraction, RT-PCR, gel electrophoresis, Southern blotting and hybridisation}

RNA was extracted from the retentate by an in-house silica beads method (Lodder and de Roda Husman, 2005) modified from the method originally described by Boom et al. (1990).

For NoV detection, we used a single round RT-PCR assay on tenfold serially diluted RNA extract (endpoint dilution) directed at the viral RNA polymerase gene (ORF1) (Vennema et al., 2002) as described previously (Lodder and de Roda Husman, 2005). NoV positive stool specimens obtained from patients with gastroenteritis were used as a positive control in the RNA extraction and the RTPCR. For rotavirus detection, we performed a RT-PCR assay for generic molecular detection of rotaviruses amplifying the VP6 gene fragment as described earlier (Villena et al., 2003). The amplification products were analysed by electrophoresis in $2 \%$ agarose gels and visualised under UV illumination after staining with SYBR Gold nucleic acid gel stain (Molecular probes, Leiden, The Netherlands) followed by specific probe hybridisation (Lodder and de Roda Husman, 2005).

\subsubsection{Cell culture of enteroviruses}

Virus infectivity was determined by a monolayer plaque assay with Buffalo Green Monkey kidney (BGM) cells (Lodder and de Roda Husman, 2005). Culture medium was removed from the BGM monolayer after which the eluate $(1.1 \mathrm{~g}$ per flask) and antibiotic mixture were added to the flasks. The positive control samples used in the cell culture method were virus isolates, coxsackievirus type B4, 
originally obtained from the 'Voorns kanaal' by BGM cell culture. The cultures were incubated at room temperature for $120 \mathrm{~min}$ and overlaid with supplemented Medium 199 agar as described before (Lodder and de Roda Husman, 2005). After 9 days of incubation at $37^{\circ} \mathrm{C}$, the cells were neutral red stained and $24 \mathrm{~h}$ later, the plaques were enumerated. The virus concentration, expressed as plaqueforming units per litre ( $\mathrm{pfu} \mathrm{L}^{-1}$ ), in the original water sample was calculated from the test volume and the virus count.

\subsection{Bacteriophage detection}

The host bacterial strain Salmonella typhimurium WG49 was exposed to the eluate to culture the F-specific bacteriophages (ISO 10705-1; Havelaar et al., 1995). The positive control used in the detection of F-specific bacteriophages was MS2 (ATCC 15597-B1). In the presence of bacteriophages, plaques could be enumerated after overnight culture at $37^{\circ} \mathrm{C}$. The virus concentration, expressed as pfu $\mathrm{L}^{-1}$, in the original water sample was calculated from the test volume and the virus count.

\subsection{Statistical methods}

\subsubsection{Calculation of virus concentrations-counts}

Counts of culturable viruses were treated as Poisson samples, assuming wellmixed suspensions. The maximum likelihood virus concentration is

$$
\mathrm{E}=\frac{\mathrm{n}}{\mathrm{H}},
$$

where $n$ is the counted number of units (virus particles or virus aggregates) and $V$ is the equivalent sample volume (the sample volume that corresponds to the amount of material applied to the cell culture). In replicate counts, the maximum likelihood concentration is

$$
\mathrm{C}=\frac{\sum_{\mathrm{i}} \mathrm{n}_{\mathrm{i}}}{\sum \mathrm{V}}
$$

(Teunis et al., 1999). The Poisson likelihood was used to calculate $95 \%$ intervals for the concentration estimates.

To describe varying virus concentrations (among separate samples), a Gamma distribution was used, as this leads to a marginal distribution which is negative binomial. By fitting the negative binomial distribution to a series of counts (in varying equivalent volumes), the parameter values for the (Gamma) probability distribution for the virus concentration can be directly estimated. Technical details are given in the Appendix.

\subsubsection{Calculation of virus concentrations-presence/absence}

Suspensions of nonculturable viruses like NoV can be titrated by using PCR to detect their presence in a dilution series of the water sample. Again assuming that particles were Poisson distributed, the probability of absence of any virus is 


$$
P(0)=\mathrm{e}^{-C V},
$$

(virus concentration $C$, equivalent sample volume $V$ ) which is used to construct a likelihood function that allows estimation of the maximum likelihood concentration $\hat{C}$ and its uncertainty (see 'Estimation of variable concentrations:

Presence/Absence' in the Appendix for technical details).

In presence/absence data, varying virus concentrations in a series of observations were also described by a Gamma distribution. Parameter estimation was based on the marginal likelihood over the sample series (outlined in 'Estimation of variable concentrations: Presence/Absence' in the Appendix). Uncertainty estimates were obtained by adaptive rejection Monte Carlo sampling, using the MetropolisHastings algorithm (Gilks et al., 1996; Teunis et al., 2004b). Virus concentrations were expressed as PCR-detectable units per litre (pdu $\mathrm{L}^{-1}$ ).

\subsubsection{Time series analysis}

Time series of observations were analysed with an adaptive dynamic filtering method. The procedure consists of two stages applied alternatingly: a prediction and a correction stage. The prediction stage uses a simple first-order dynamic model (a single compartment) to predict the virus concentration after the current sample. When a new sample is taken, a Bayesian correction is applied, using the predicted concentration as prior information yielding a posterior corrected estimate for the parameters of the virus concentration, allowing calculation of a new (corrected) concentration estimate. Then the prediction cycle starts again, until a new sample arrives and another correction stage can be done. This approach is equivalent to the well-known Kalman filter. Technical details are given in the 'Bayesian forecasting' section in the Appendix.

\section{Results}

The monthly concentrations of NoV, enteroviruses, F-specific bacteriophages and turbidity from the river Meuse during 2001 at the source water intake of a drinking water company are presented in Fig. 1 . The NoV were present in the surface water in high concentrations during the winter months with a maximum concentration of approximately $240 \mathrm{pdu} \mathrm{L}^{-1}$ in January (Fig. 1a). No samples were positive between the middle of February until the beginning of October, except for one in May ( $\left.2.5 \mathrm{pdu} \mathrm{L}^{-1}\right)$. Rotaviruses could not be detected in any samples during 2001. Enteroviruses on the other hand were detectable throughout the whole year of 2001, ranging in concentration from 0.003 to $0.90 \mathrm{pfu} \mathrm{L}^{-1}$, with minor peaks in March-April and October-December (Fig. 1b). F-specific bacteriophages were the most numerous, ranging from 6 to 7400 pfu $\mathrm{L}^{-1}$ with the highest numbers found in February and the end of November (Fig. 1C). Turbidity levels were considerably increased in March and April as compared to the rest of the year (Fig. 1d). A common trend for all measured viruses and turbidity was the occurrence of two coinciding peaks early 2001 (January-April) and late 2001 (October-December). 


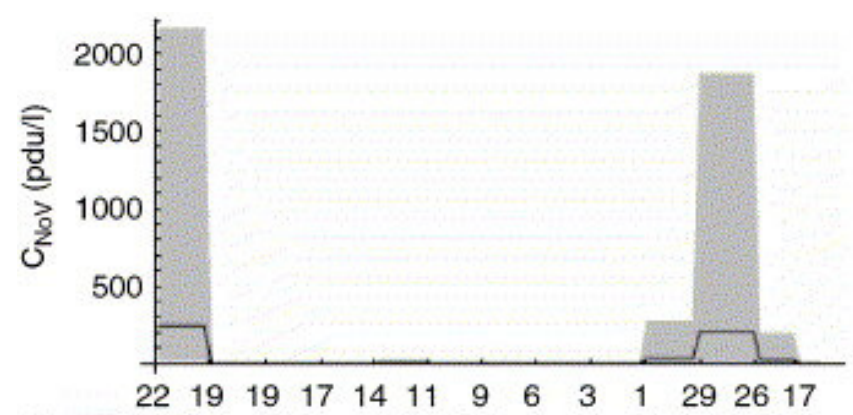

(a) jan feb mar apr may jun jul aug sep oct oct novdec

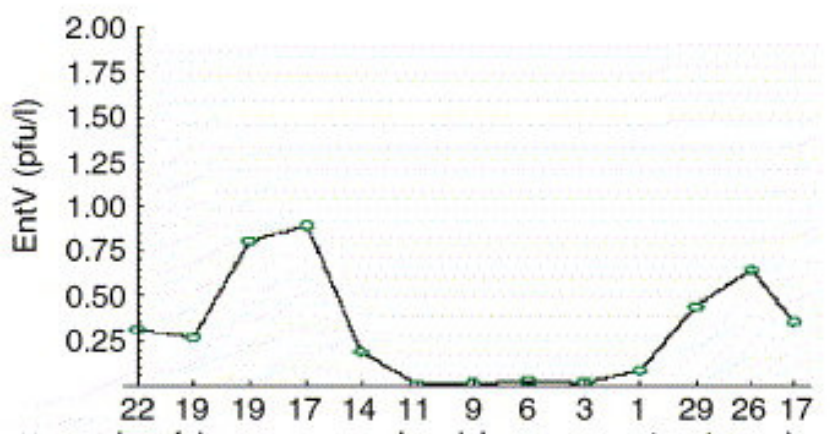

(b) jan feb mar apr may jun jul aug sep oct oct novdec

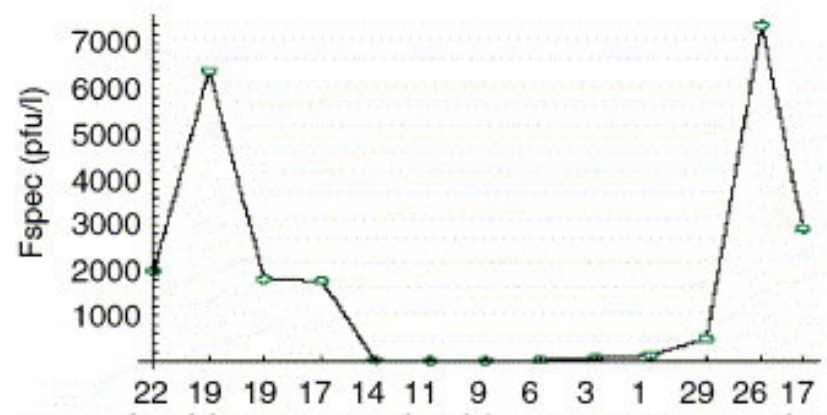

(c) jan feb mar apr may jun jul aug sep oct oct novdec

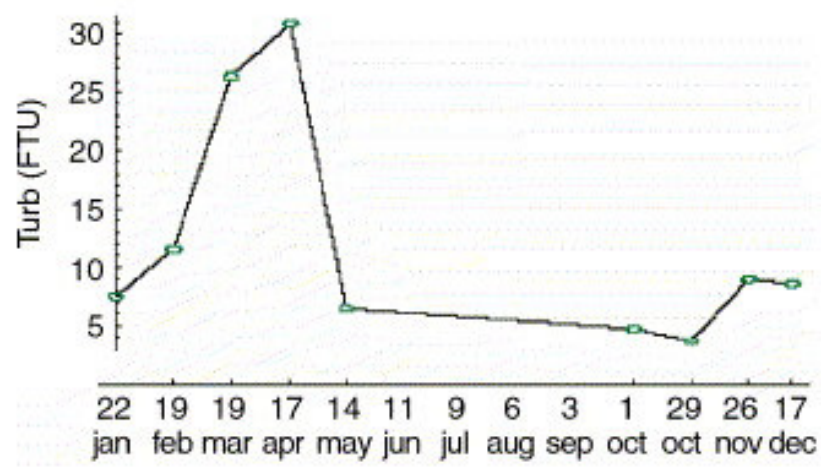

Fig. 1. Concentration of (a) noroviruses $\left(\mathrm{pdu} \mathrm{L}^{-1}\right)$, (b) enteroviruses $\left(\mathrm{pfu} \mathrm{L}^{-1}\right)$ and (c) F-specific bacteriophages (pfu $\mathrm{L}^{-1}$ ), and (d) turbidity (FTU) at Keizersveer, river Meuse, during sampling in 2001. The NoV concentration (a) is based on MPN calculations and show the mean and $95 \%$ confidence interval. The concentrations of the other microbial parameters are based on counts ( $b$ and $c$ ).

Since the high NoV levels ( $>100$ pdu $\mathrm{L}^{-1}$ ) only occurred in water samples during wintertime, the short time variability was further assessed in an intensified 
sampling programme with weekly large water samples (200-500 L) and intermediate small water samples (10 L) during December 2002-January 2003. The results are presented in Fig. 2. NoV were detected in all samples, ranging from a mean of 12 to 1700 pdu L ${ }^{-1}$ (Fig. 2a). Compared to the NoV peak concentrations of approximately $200 \mathrm{pdu} \mathrm{L}^{-1}$ in 2001 (Fig. 1), the levels were approximately tenfold higher (2000-3000 pdu L ${ }^{-1}$ ) in 2002/2003. Fig. $2 b$ shows the time course of NoV concentrations as estimated with the time series algorithm. As can be seen, the adaptive filter is adjusted to predict forthcoming sample concentrations accurately, with a narrower $95 \%$ confidence interval than that of the single MPN estimate (Fig. 2a). The intensified sampling revealed that the winter peak consisted of not one but several shorter peaks of varying magnitude and duration. Two peaks in the order of $600 \mathrm{pdu} \mathrm{L}^{-1}$, lasting 1 day each, were detected on December 12 and January 7 . Three higher peaks in the order of 1500-1700 pdu L $\mathrm{L}^{-1}$, lasting from 1 to 4 days, were detected on

December 31, and January 2 and 10. In contrast with 2001, one sample in 2002 (December 30) was found positive for the presence of rotavirus at $32 \mathrm{pdu} \mathrm{L}^{-1}$. The concentration of F-specific bacteriophages was fairly constant during the sampling period (median $1300 \mathrm{pfu} \mathrm{L}^{-1}$ ) except for a peak of $5100 \mathrm{pfu} \mathrm{\textrm {L } ^ { - 1 }}$ in the second half of December (Fig. 2c). There was a marked increase in turbidity over the sampling course with two distinct peaks in the beginning of January at 69 and 67 NTU, respectively (Fig. 2d). In contrast with the 2001 observations, fluctuations in F-specific bacteriophages and turbidity now did not coincide with the observed peaks in NoV concentrations. 

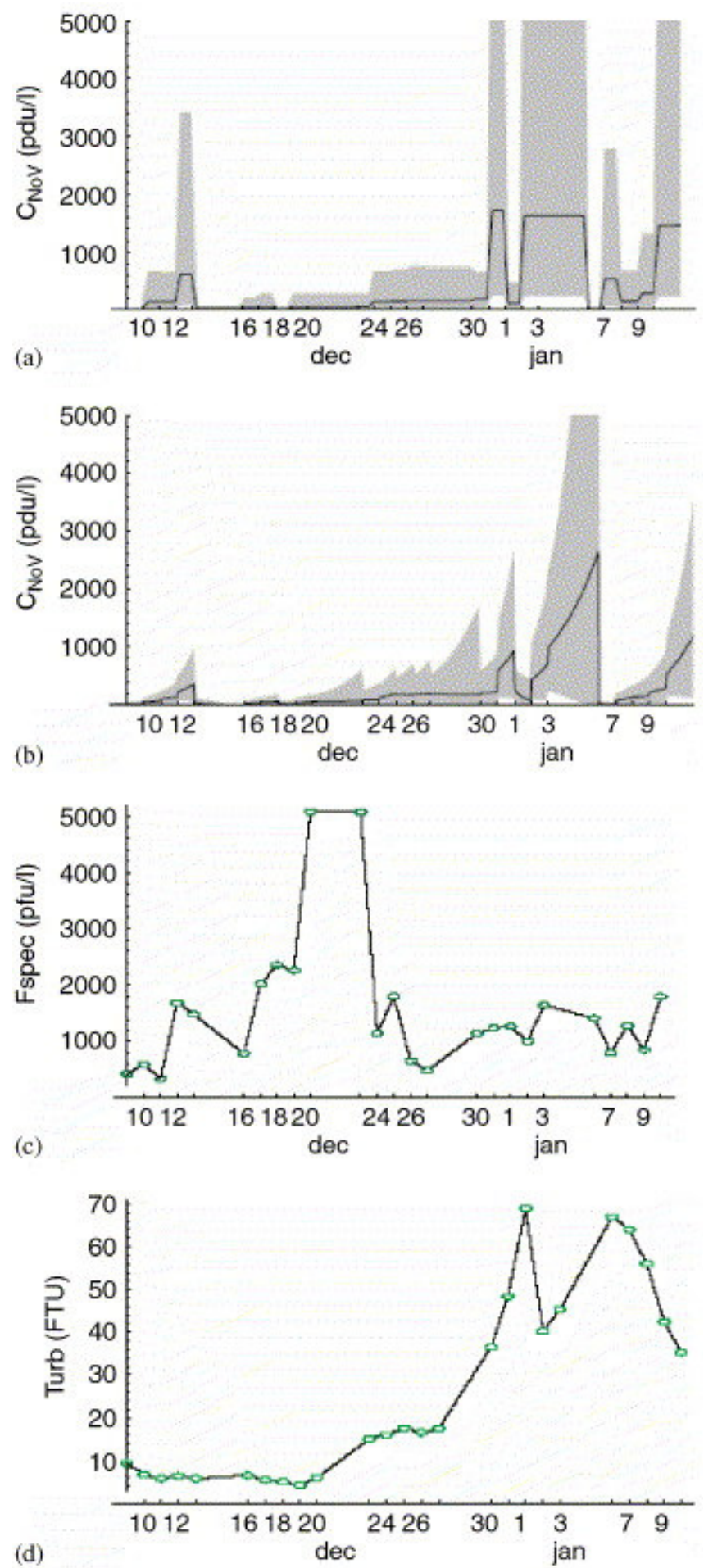

Fig. 2. Concentration of (a) noroviruses with MPN, (b) noroviruses with time series analysis and (c) F-specific bacteriophages ( $\mathrm{pfu} \mathrm{L}^{-1}$ ), and (d) turbidity (FTU) at Keizersveer, river Meuse, during intensified sampling in December-January 2002-2003. The NoV concentration based on MPN calculations (a) show the mean and $95 \%$ confidence interval. In the time series analysis (b), the black line represents the mean while the shaded area is the $95 \%$ predictive interval for the concentration. Large volume water samples were on December 9, 16, 23, 30 and 
January 6 , each followed by small volume water samples on the four consecutive days.

The concentration of NoV in water in a collection of several samples can also be expressed as a frequency distribution to visualise the frequency distribution of the different NoV concentrations in either sampling period. The peaks found in 2001 corresponded to the 95 percentile of the Gamma distribution for 2001, i.e. the peak concentrations found in 2001 were estimated to occur during $5 \%$ of the year (Fig. 3a and Table 1). Based on the data collected during the winter of 2002/2003, peaks were predicted to occur even more frequently (Fig. $3 \mathrm{~b}$ ). The annual median concentration in 2001 based on the probability density function was 0.062 pdu L ${ }^{-1}$ compared to a median of 151 pdu L $\mathrm{L}^{-1}$ during the winter peak in 2002/2003 (Table 1). Levels of the same magnitude as the peaks in 2001 were calculated to occur during $30 \%$ of the time and levels of 1000 pdu L $\mathrm{L}^{-1}$ or more during $0.4 \%$ of the time (data not shown).
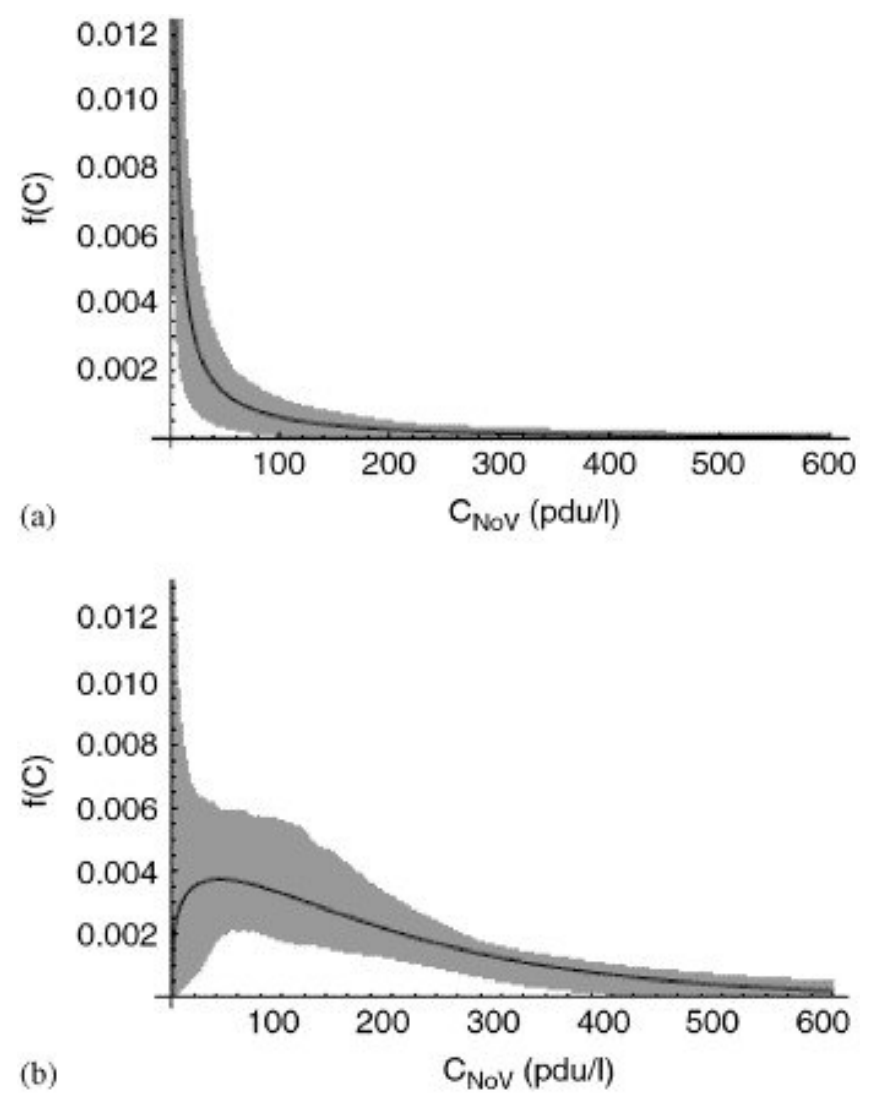

Fig. 3. Probability density functions of norovirus concentrations $\left(\mathrm{L}^{-1}\right)$ in the Keizersveer expressed as Gamma distributions for (a) the whole year of 2001, and (b) intensified sampling during December 2002-January 2003. Maximum likelihood parameter values of $a$ and $\lambda$ are for (a) 0.0855 and 370.2 and for (b) 1.273 and 158.4, respectively. The shaded area represents the $95 \%$ confidence interval estimated with Monte Carlo techniques. 
Table 1.

Mean and quantiles for the Gamma probability distributions fitted to the norovirus concentrations (pdu L ${ }^{-1}$ ) measured in 2001 and in December-January 2002-2003

\begin{tabular}{|l|c|c|c|c|c|}
\hline & Mean & Median & $\mathbf{0 . 9 0}$ & $\mathbf{0 . 9 5}$ & $\mathbf{0 . 9 9}$ \\
\hline Whole year 2001 & 33.3 & 0.062 & 81.4 & 194 & 577 \\
\hline Winter peak 02/03 & 200 & 151 & 433 & 550 & 815 \\
\hline
\end{tabular}

\section{Discussion}

NoV to date cannot be cultured (Duizer et al., 2004) making it impossible to collect data that are both informative on the numbers and infectious state of the detected viruses. However, since NoV are the most important agents of gastroenteritis and can be transmitted via water, they should be taken into account when considering waterborne public health risks. Since virus concentrations in drinking waters are generally below the detection limit, the infection risk from drinking water consumption can only be assessed indirectly from the virus concentrations in source waters and removal efficiency of applied treatment processes. NoV concentrations in source waters need to be quantified for which a real-time, quantitative RT-PCR assay would be useful. Recently, a real-time Nucleic Acid Sequence Based Amplification assay was developed for enteroviruses in water (Rutjes et al., 2005); however, such an assay has not yet been described for NoV detection in water. In this study, we used classical statistical methods to estimate NoV concentrations from the presence or absence of viral RNA serially diluted water concentrates. In our previous studies, NoV concentrations in Dutch sewage and surface waters were estimated but not in source waters for drinking water production (van den Berg et al., 2005, Lodder and de Roda Husman, 2005). For quantitative NoV risk assessment, we not only need average concentrations of NoV in source waters but also knowledge on possible fluctuations. Variations in NoV concentrations in source waters result in a highly skewed distribution with a small probability of being exposed to a high dose of NoV in drinking water. The NoV concentrations found in the river water in $2002 / 2003$ were considerably higher than those found in the same months of 2001. A possible explanation for this is the outstanding increase in NoV outbreaks reported in Europe during 2002 (Lopman et al., 2004). The increase in number of outbreaks in The Netherlands was $128 \%$ compared to the maximum from 1995 to 2001 . With the intensified sampling done in $2002 / 2003$, we were able to resolve the seasonal peak as seen in 2001 . For NoV, the winter peak appeared to consist of several peaks of varying duration and magnitude. These patterns may in fact be due to different types of events. Heavy rainfall can cause combined sewer overflows leading to untreated sewage being released into the recipient. It can also cause substantial run-off from pastureland, contaminating the water with animal caliciviruses. Variability or even failure in sewage treatment is another possible event. An alternative explanation could be that the peaks reflect the occurrence of different NoV variants in the water. Since they could originate from different sources, be introduced at different time points and/or differ in their survival, this could give rise to the observed pattern. During 2002, however, the majority of outbreaks (76\%) in the Dutch population was attributed to a single NoV strain, a new variant of GII4 (Lopman et al., 2004). More study is warranted to investigate the causes of these short-term fluctuations. One thing must be noted, without the intensified sampling (five samples per week compared to monthly samples), some of the peaks would have passed unnoticed since they only lasted from 1 to 4 days. Even the weekly large volume water sampling was 
insufficient in detecting the peaks (Fig. 2a). This is most likely an effect of the temporal variability in virus concentrations in the water. Such short-term fluctuations are relevant for estimation of long-term risk (or exposure), as their accurate estimation requires intense sampling. The long-term accumulated risk then depends mainly on the occurrence of concentration peaks (Teunis and Havelaar, 1999; Teunis et al 2004a) and the risk becomes 'event-driven' (also sometimes called 'bad days').

The peaks in NoV during the intensified sampling did not coincide with the peak in F-specific bacteriophages. On the other hand, peaks in turbidity also occurred during this second half of the sampling period. The use of indicators for predicting pathogen occurrence and concentrations in water environments has been much debated (Ashbolt et al., 2001). LeChevallier et al. (2001) did an extensive study on protozoan parasites and indicators in surface waters of different types and pollution levels. Although the coincidence of pathogens and indicators implied a common cause when looking at the monthly samples, the pattern changed when the sampling was intensified and they were not able to find any significant correlation between the pathogens and the indicators. Here, we show the importance of analysing source waters for NoV since indicators may give misleading results.

Time series analysis may be attractive for risk management as it can act as an early warning system. In time series analysis, all previous information collected up to a certain point supports forecast of future changes in concentration, separating an increase or decrease in concentration from random fluctuations. In fact, Bayesian dynamic forecasting was originally designed for this purpose (West, 1997). Teunis et al. (2004a) applied the same type of analysis on the data of LeChevallier et al. (2001) as in this paper and recommended its use in HACCP, both for monitoring and risk assessment purposes. For reliable forecasting, it is, however, important that sampling is frequent and the detection method rapid enough to allow detection of short-term fluctuations. Such an early warning system also gives the opportunity to control for events. For example, if any new measurement exceeds the predicted level (based on the history of observations), a warning could be generated that action should be taken. Thus, a rational and efficient decision tool may be designed, which can provide real-time information on source water quality and is a useful addition to more traditional statistical methods used to control public health.

\section{Conclusions}

- Noroviruses (NoV) were found in the river Meuse predominantly during the winter season, concurrent in time with NoV outbreaks in the Dutch population.

- Intensified sampling revealed that the winter peak consisted of several shorter peaks of varying duration and magnitude. This could possibly be a result of different types of events in the catchment or due to the presence of different NoV variants.

- Peaks in NoV did not coincide with those of enteroviruses, F-specific bacteriophages or turbidity.

- The concentrations of NoV estimated from the water samples constitute a significant health risk to people using the water and could also involve transmission of the viruses via drinking water if the treatment is insufficient. The highest estimated concentration of NoV was $1700 \mathrm{pdu} \mathrm{L}^{-1}$. 
- Adaptive dynamic forecasting allows prediction of forthcoming sample concentrations based on previous samples, providing a means for early detection of contamination events. This may be a useful tool in risk management of source waters.

\section{Acknowledgements}

This work was funded in part by Waterleidingbedrijf Brabantse Biesbosch and the Environmental Inspectorate under project number 330000, Health Related Water Microbiology. Additional financial support was provided by the Swedish research programme Sustainable Urban Water Management. All data are available on request.

\section{References}

Allwood et al., 2003 P.B. Allwood, Y.S. Malik, C.W. Hedberg and S.M. Goyal, Survival of F-specific RNA coliphage, feline calicivirus, and Escherichia coli in water: a comparative study, Appl. Environ. Microbiol. 69 (2003) (9), pp. 5707-5710.

Anderson, 2003 A.D. Anderson, A.G. Heryford, J.P. Sarisky, C. Higgins, S.S. Monroe, R.S. Beard, C.M. Newport, J.L. Cashdollar, G.S. Fout, D.E. Robbins, S.A. Seys, K.J. Musgrave, C. Medus, J. Vinje, J.S. Bresee, H.M. Mainzer and R.I. Glass, A waterborne outbreak of Norwalk-like virus among snowmobilers-Wyoming, 2001, J. Infect. Dis. 187 (2003) (2), pp. 303-306.

Ashbolt et al., 2001 N.J. Ashbolt, W.O.K. Grabow and M. Snozzi, Indicators of microbial water quality. In: L. Fewtrell and J. Bartram, Editors, Water Quality: Guidelines, Standards and Health IWA Publishing, London (2001), pp. 289-316.

Boom et al., 1990 R. Boom, C.J.A. Sol, M.M.M. Salimans, C.L. Jansen, P.M.E. Wertheimvandillen and J. Vandernoordaa, Rapid and simple method for purification of nucleic-acids, J. Clin. Microbiol. 28 (1990) (3), pp. 495-503.

Brown et al., 2001 C.M. Brown, J.W. Cann, G. Simons, R.L. Fankhauser, W. Thomas, U.D. Parashar and M.J. Lewis, Outbreak of Norwalk virus in a Caribbean island resort: application of molecular diagnostics to ascertain the vehicle of infection, Epidemiol. Infect. 126 (2001) (3), pp. 425-432.

Cox and Hinkley, 1974 D.R. Cox and D.V. Hinkley, Theoretical Statistics, Chapman \& Hall, London (1974).

Duizer et al., 2004 E. Duizer, K.J. Schwab, F.H. Neill, R.L. Atmar, M.P. Koopmans and M.K. Estes, Laboratory efforts to cultivate noroviruses, J. Gen. Virol. 85 (2004) (Part 1), pp. 79-87.

Gilks et al., 1996 In: W. Gilks, S. Richardson and D. Spiegelhalter, Editors, Markov Chain Monte Carlo in practice, Chapman \& Hall, London (1996).

Havelaar et al., 1995 A.H. Havelaar, M. van Olphen and J.F. Schijven, Removal and inactivation of viruses by drinking water treatment processes under full scale conditions, Water Sci. Technol. 31 (1995) (5-6), pp. 55-62.

Hedlund, 2004 K.-O. Hedlund, Personal communication, Swedish Institute for Infectious Disease Control, Solna, Sweden (2004).

Hoebe et al., 2004 C.J. Hoebe, H. Vennema, A.M. de Roda Husman and Y.T. van Duynhoven, Norovirus outbreak among primary schoolchildren who had played in a recreational water fountain, $J$. Infect. Dis. 189 (2004) (4), pp. 699-705.

Hörman et al., 2004 A. Hörman, R. Rimhanen-Finne, L. Maunula, C.H. von Bonsdorff, N. Torvela, A. Heikinheimo and M.L. Hänninen, Campylobacter spp., Giardia spp., Cryptosporidium spp., noroviruses, 
and indicator organisms in surface water in southwestern Finland, 2000-2001, Appl. Environ. Microbiol. 70 (2004) (1), pp. 87-95.

Katayama et al., $2002 \mathrm{H}$. Katayama, A. Shimasaki and S. Ohgaki, Development of a virus concentration method and its application to detection of enterovirus and norwalk virus from coastal seawater, Appl. Environ. Microbiol. 68 (2002) (3), pp. 1033-1039.

Koopmans and Duizer, 2004 M. Koopmans and E. Duizer, Foodborne viruses: an emerging problem, Int. J. Food Microbiol. 90 (2004) (1), pp. 23-41.

LeChevallier et al., 2001 LeChevallier, M.W., Di Giovanni, G., Clancy, J.L., Bukhari, S., Rosen, J.S., Sobrinho, J., Frey, M.M., 2001. Variability of Giardia and Cryptosporidium concentrations in surface water. Technical Report, American Water Works Service Company Inc.

Lindesmith et al., 2003 L. Lindesmith, C. Moe, S. Marionneau, N. Ruvoen, X. Jiang, L. Lindblad, P. Stewart, J. LePendu and R. Baric, Human susceptibility and resistance to Norwalk virus infection, Nat. Med. 9 (2003) (5), pp. 548-553.

Lodder and de Roda Husman, 2005 W.J. Lodder and A.M. de Roda Husman, Presence of noroviruses and other enteric viruses in sewage and surface waters in The Netherlands, Appl. Environ. Microbiol. 71 (2005) (3), pp. 1453-1461.

Lodder et al., 1999 W.J. Lodder, J. Vinjé, R. van de Heide, A.M. de Roda Husman, E.J.T.M. Leenen and M.P.G. Koopmans, Molecular detection of Norwalk-like caliciviruses in sewage, Appl. Environ. Microbiol. 65 (1999) (12), pp. 5624-5627.

Lopman et al., 2004 B. Lopman, H. Vennema, E. Kohli, P. Pothier, A. Sanchez, A. Negredo, J. Buesa, E. Schreier, M. Reacher, D. Brown, J. Gray, M. Iturriza, C. Gallimore, B. Bottiger, K. Hedlund, M. Torven, C. von Bonsdorff, L. Maunula, M. Poljsak-Prijatelj, J. Zimsek, G. Reuter, G. Szucs, B. Melegh, L. Svennson, Y. van Duijnhoven and M. Koopmans, Increase in viral gastroenteritis outbreaks in Europe and epidemic spread of new norovirus variant, Lancet 363 (2004) (9410), pp. 682-688.

Marshall et al., 2001 J.A. Marshall, S. Salamone, L. Yuen, M.G. Catton and J.P. Wright, High level excretion of Norwalk-like virus following resolution of clinical illness, Pathology 33 (2001) (1), pp. 5052.

Mounts et al., 2000 A.W. Mounts, T. Ando, M. Koopmans, J.S. Bresee, J. Noel and R.I. Glass, Cold weather seasonality of gastroenteritis associated with Norwalk-like viruses, J. Infect. Dis. 181 (2000) (Suppl. 2), pp. S284-S287.

Nygård et al., 2003 K. Nygård, M. Torvén, C. Ancker, S.B. Knauth, K.O. Hedlund, J. Giesecke, Y. Andersson and L. Svensson, Emerging genotype (GGIIb) of norovirus in drinking water, Sweden, Emerg. Infect. Dis. 9 (2003) (12), pp. 1548-1552.

Rockx et al., 2002 B. Rockx, M. De Wit, H. Vennema, J. Vinje, E. De Bruin, Y. Van Duynhoven and M. Koopmans, Natural history of human calicivirus infection: a prospective cohort study, Clin. Infect. Dis. 35 (2002) (3), pp. 246-253.

Rutjes et al., 2005 S.A. Rutjes, R. Italiaander, Berg, HHJL van den, W.J. Lodder and Roda Husman, AM de, Isolation and detection of enterovirus RNA from large volume water samples using the NucliSens miniMAG system and real-time NASBA amplification, Appl. Environ. Microbiol. 71 (2005), pp. 3734-3740.

Teunis and Havelaar, 1999 Teunis, P.F.M., Havelaar, A.H., 1999. Cryptosporidium in drinking water: evaluation of the ILSI quantitative risk assessment framework. RIVM Report 28455006.

Teunis et al., 2004a P. Teunis, A. Davison and D. Deere, Short term fluctuations in drinking water quality and their significance for public health, World Health Organization Report, Geneva (2004).

Teunis et al., 2004b P. Teunis, K. Takumi and K. Shinagawa, Dose response for infection by Escherichia coli O157:H7 from outbreak data, Risk Anal. 24 (2004) (2), pp. 401-407. 
van den Berg et al., 2005 H. van den Berg, W. Lodder, W. van der Poel, H. Vennema and A.M. de Roda Husman, Genetic diversity of noroviruses in raw and treated sewage, Res. Microbiol. 156 (2005), pp. 532-540.

Vennema et al., $2002 \mathrm{H}$. Vennema, E. de Bruin and M. Koopmans, Rational optimization of generic primers used for Norwalk-like virus detection by reverse transcriptase polymerase chain reaction, $J$. Clin. Virol. 25 (2002) (2), pp. 233-235.

Villena et al., 2003 C. Villena, W.M. El-Senousy, F.X. Abad, R.M. Pinto and A. Bosch, Group a rotavirus in sewage samples from Barcelona and Cairo: emergence of unusual genotypes, Appl. Environ. Microbiol. 69 (2003) (7), pp. 3919-3923.

West, 1997 M. West, Bayesian Forecasting and Dynamic Models (second ed), Springer, New York (1997).

\section{Appendix A. Technical details}

\section{Estimation of variable concentrations}

\section{Negative binomial counts}

If we take a sample of volume $V$ from a well-mixed suspension of microbes with concentration $C$, and Poisson distributed counts

$$
\mathrm{p}(\mathrm{k} \mid \mathrm{c}, \mathrm{V})=\frac{(\mathrm{cV}) \mathrm{ke}^{-\mathrm{cV}}}{\mathrm{k} !},
$$

and assume $c$ varies between samples, with Gamma variation

$$
\mathrm{f}(\mathrm{c} \mid \mathrm{i}, \lambda)=\frac{\lambda^{-\mathrm{x}}}{\Gamma(\mathrm{r})} \mathrm{c}^{\mathrm{t}-1} \mathrm{e}^{-\mathrm{c} / \lambda}
$$

the marginal distribution for the counts is

$$
\mathrm{g}(\mathrm{k} \mid \mathrm{r}, \lambda)=\frac{\Gamma(\mathrm{k}+\mathrm{r})}{\mathrm{k} ! \Gamma(\mathrm{r})} \frac{(\mathrm{V})}{(1+\lambda \mathrm{V})}
$$

If we substitute $1 /(1+\lambda V)=p$, this may be rewritten into the familiar equation for the negative binomial distribution. This relation, expressing the distribution of counts as a function of parameters of a Gamma distributed concentration, can be used to calculate a predictive interval for the time series of counts.

\section{Presence/absence}

In case the only information we have is presence or absence of the organism in a sample (volume $V$ ), we can still estimate concentrations. Usually, a dilution series is made, diluting the original sample by a fixed factor several times, and determining at which dilution the organism is not detected anymore. If a positive test result (presence) is indicated by ' 1 ', and a negative result (absence) by ' 0 ', the observations can be summarised in a binary vector $\boldsymbol{u}$. The likelihood function can then be written as 


$$
L(c \mid u, \rho, V)=\|_{i}\left(1-u_{i} e^{-c W / h) e^{-n, V / h}}\right.
$$

where $V$ is the sample volume; $\rho_{i}$ indicates the dilution at stage $i$, usually this equals $\rho^{i}$. If we have a Gamma distributed concentration $f(c \mid r, \rho)$, the marginal distribution

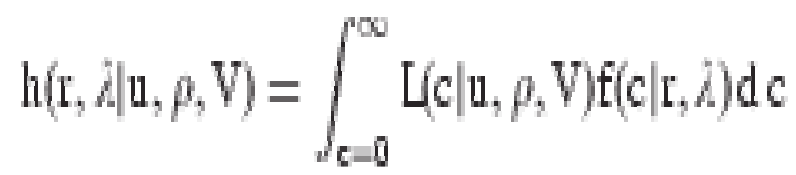

can be used to estimate the distribution of virus concentrations for a series of samples.

\section{Bayesian forecasting}

\section{Counts: Bayesian concentration estimate}

If suspended organisms are distributed at random in a sample of volume $V$ with a concentration $c$, counts are Poisson distributed:

$$
\Gamma(k \mid c, v)-\frac{e^{-c v}(c V)^{k}}{k !}
$$

Using a Gamma prior for the concentration c (Cox and Hinkley, 1974),

$$
\mathrm{f}(\mathrm{c} \mid \mathrm{i}, \lambda)=\frac{\lambda^{-\mathrm{i}}}{\Gamma(\mathrm{x})} \mathrm{c}^{\mathrm{t}-1} \mathrm{e}^{-\mathrm{c} / \lambda}
$$

leads to a posterior degree of freedom (d.f.) for $c$ (given $k$ ) which is also Gamma:

$$
g(c), V, r, h)=\frac{\left(\frac{\lambda}{1+N}\right)^{-(1+i)}}{1(k+r)} \mu^{L+1-1} \mathrm{e}^{-c /(\nu /(1+N))}
$$

So that the parameters are converted to

$$
\mathrm{r} \rightarrow \mathrm{k}+\mathrm{r} ; \quad \mathrm{h} \rightarrow \frac{\mathrm{h}}{\mathrm{l}+\mathrm{JV}}
$$

Presence/absence: Bayesian concentration estimate

Using the likelihood function given previously and a Gamma prior $f(c \mid r, \lambda)$ for the concentration, the posterior d.f. is 


$$
g(c \mid u, p, V, r, \lambda)=\frac{L(c \mid u, p, V) f(c \mid r, \lambda)}{\int_{c=0}^{\infty} L(c \mid u, p, V):(c \mid r, \lambda) d c},
$$

which in general is not a Gamma distribution. This posterior distribution of $c$ can, however, be used to calculate its expectation and variance and we can determine the parameters of a Gamma distribution with the same mean and variance

$$
\begin{aligned}
& \lambda \rightarrow \frac{[E(c)]^{2}-E(c)^{2}}{E(c)}=E(c)\left(1-\frac{E\left(c^{2}\right)}{[E(c)]^{2}}\right), \\
& \lambda \rightarrow \frac{[E(c)]^{2}}{[E(c)]^{2}-E\left(c^{2}\right)}=\frac{1}{1-\frac{E\left(c^{2}\right)}{[E(c)]^{2}}}
\end{aligned}
$$

and use these as an approximate corrected prior for the next update of the filter.

\section{Prediction}

Assuming a first-order system, the mean concentration changes with time exponentially. For a given constant $a$, the predicted concentration at time $t$ after start $t_{0}$ is

$$
\mu_{c, \text { pred }}(t)=\mu_{c, t 0} \mathrm{e}^{a(t-t)} .
$$

The variance in the predicted concentration (the system noise) increases exponentially with time

$$
\sigma_{\text {cpred }}^{2}(t)=\sigma_{c_{0}}^{2} e^{d+10 b}
$$

With a Gamma distributed concentration, this can be written as

$$
\mu_{c p r e d}(t)=\mathrm{r}_{1_{0}} \lambda_{0} \mathrm{e}^{\mathrm{a}\left(\mathrm{i}-\mathrm{t}_{0}\right)} ; \quad \sigma_{\text {cpred }}^{2}(\mathrm{t})=\mathrm{r}_{1_{0}} \lambda_{0}^{2} \mathrm{e}^{\mathrm{i}\left(1-\mathrm{t}_{0}\right)}
$$

or

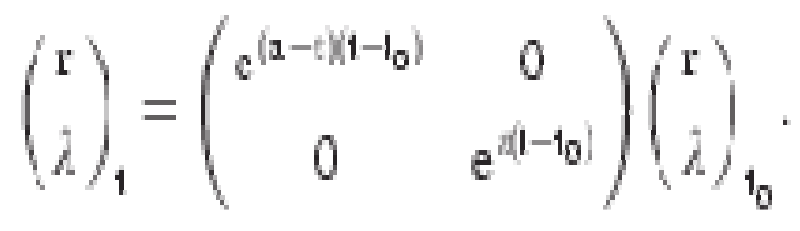

\section{Correction}

If, at time $t_{1}$ since the previous sample in a volume $V$ a number $k$ organisms are counted, the posterior estimates of the Gamma parameters, as given above, are 
Water Research Volume 40, Issue 14 , August 2006, Pages 2613-2620

$$
\tilde{\mathrm{r}}=\mathrm{k}+\mathrm{r}, \quad \tilde{\lambda}=\frac{\lambda}{1+\lambda \mathrm{V}},
$$

and we may express the new expected (mean) concentration as a function of the old (predicted) one and obtain a new value for the first-order constant $a$ :

$$
\tilde{\mu}_{c, 1}=\tilde{r}=\frac{(\mathrm{k}+\mathrm{r}) \lambda}{1+\lambda \mathrm{V}}=\mathbf{r} \lambda e^{\mathrm{i} 1},
$$

so that

$$
\tilde{\mathbf{a}}=\frac{1}{t_{1}} \log \left(\frac{k+r}{r(1+\lambda V)}\right) \text {. }
$$

* Corresponding author. Tel.: +3130274 4325; fax: +3130274 4434 . 